\title{
Plasma tau correlates with basal forebrain atrophy rates in people at risk for Alzheimer disease
}

Enrica Cavedo, PhD, Simone Lista, PhD, Marion Houot, MS, Andrea Vergallo, MD, Michel J. Grothe, PhD, Stefan Teipel, MD, Henrik Zetterberg, MD, PhD, Kaj Blennow, MD, Marie-Odile Habert, MD,

Marie C. Potier, PhD, Bruno Dubois, MD, and Harald Hampel, MD, PhD,

for the INSIGHT-preAD Study Group and the Alzheimer Precision Medicine Initiative

Neurology ${ }^{\circledR}$ 2020;94:e1-e12. doi:10.1212/WNL.0000000000008696

\section{Abstract \\ Objective}

To investigate whether baseline concentrations of plasma total tau ( $\mathrm{t}$-tau) and neurofilament light (NfL) chain proteins are associated with annual percent change (APC) of the basal forebrain cholinergic system (BFCS) in cognitively intact older adults at risk for Alzheimer disease $(\mathrm{AD})$.

\section{Methods}

This was a large-scale study of 276 cognitively intact older adults from the monocentric INSIGHT-preAD (Investigation of Alzheimer's Predictors in Subjective Memory Complainers) cohort. Participants underwent baseline assessment of plasma t-tau and NfL concentrations as well as baseline and 24-month follow-up MRI scans. Linear models with and without influential observations (calculated using the Cook distance) were carried out to investigate the effect of plasma NfL and t-tau concentrations, and their interaction effect with $\beta$-amyloid status and APOE genotype, on the APC of the whole BFCS and its anterior $(\mathrm{Ch} 1 / 2)$ and posterior (Ch4) subdivisions separately.

\section{Results}

Higher plasma $\mathrm{t}$-tau concentrations at baseline were associated with higher BFCS rate of atrophy (model without influencers: $\mathrm{n}=251, \mathrm{~F}$ value $=4.6815 ; p$ value $=0.031$ ). Subregional analyses showed similar results for both the APC of the Ch1/2 (model without influencers: $\mathrm{n}=$ 256, $\mathrm{F}$ value $=3.9535, p$ corrected $=0.047$ ) and Ch4 BFCS sectors (model without influencers: $\mathrm{n}=253, \mathrm{~F}$ value $=4.9090, p$ corrected $=0.047)$. Baseline NfL, $\beta$-amyloid load, and APOE $\varepsilon 4$ carrier status did not affect APC of the BFCS.

\section{Conclusion}

Increased concentrations of baseline plasma t-tau may predict in vivo structural BFCS atrophy progression in older adults at risk for $\mathrm{AD}$, independently of $\beta$-amyloid status and $A P O E$ genotype.

\author{
Correspondence \\ Dr. Cavedo \\ enrica.cavedo@gmail.com
}




\section{Glossary}

$\mathbf{A} \boldsymbol{\beta}=\beta$-amyloid $\mathbf{A D}=$ Alzheimer disease $\mathbf{A P C}=$ annualized percentage change $\mathbf{B F C S}=$ basal forebrain cholinergic system; INSIGHT-preAD = Investigation of Alzheimer's Predictors in Subjective Memory Complainers; $\mathrm{MCI}=$ mild cognitive impairment; NBM = nucleus basalis of Meynert; NfL = neurofilament light; $\mathbf{Q C}=$ quality control; SUVR = standard uptake value ratio; $\mathbf{t}$-tau $=$ total tau; $\mathbf{T B I}=$ traumatic brain injury; $\mathbf{T I V}=$ total intracranial volume; $\mathbf{W M}=$ white matter.

Human neuropathologic studies showed that tau-induced neuronal damage and cell loss in the nucleus basalis of Meynert (NBM) is one of the earliest pathophysiologic events in Alzheimer disease $(\mathrm{AD}) .{ }^{1-3}$ Further findings indicate that the cholinergic lesions occurring in the NBM in patients with $\mathrm{AD}$ are closely related to tauopathy and not to $\beta$-amyloid (A $\beta$ ) pathophysiology. ${ }^{4-7}$ Moreover, it is wellestablished that cognitive decline is associated with taumediated lesions of basal forebrain cholinergic system (BFCS) neurons even before the deposition of neurofibrillary tangles (the so-called pretangle stages). ${ }^{8}$

MRI-based measurement of BFCS atrophy represents a candidate in vivo surrogate marker of $\mathrm{AD}$-related neurodegeneration in both clinical and preclinical populations. ${ }^{9-11}$

Blood-based biomarkers of neuronal injury, including plasma total tau ( $\mathrm{t}$-tau) and plasma axonal neurofilament light (NfL) chain protein, are candidate surrogate biomarkers of neurodegeneration. ${ }^{12}$ Significant correlations between high baseline concentrations of plasma t-tau and future cognitive decline, ${ }^{13}$ as well as increased brain atrophy rates and brain glucose hypometabolism, ${ }^{14}$ were found in cognitively normal older adults and patients with $\mathrm{AD}$ dementia. Furthermore, in individuals with mild cognitive impairment (MCI), plasma NfL concentrations were found to be highest in patients with a positive amyloid PET scan, and predicted faster cognitive deterioration, faster brain atrophy rate, and glucose hypometabolism. ${ }^{15}$

Based on evidence of BFCS involvement in early $\mathrm{AD}$ pathology, ${ }^{16}$ we investigated the question whether plasma $t$-tau and NfL concentrations affect rates of BFCS atrophy as surrogate markers of cholinergic basal forebrain degeneration in cognitively intact older adults with subjective memory complaints, a condition with increased risk for $\mathrm{AD}$.

\section{Methods}

\section{Participants}

Participants were recruited in the Investigation of Alzheimer's Predictors in Subjective Memory Complainers (INSIGHTpreAD) study, part of the Alzheimer Precision Medicine Initiative Cohort Program. ${ }^{17,18}$ Participants were enrolled at the Institute of Memory and Alzheimer's Disease (Institut de la Mémoire et de la Maladie d'Alzheimer [IM2A]) at the PitiéSalpêtrière University Hospital in Paris, France. The main purpose of the INSIGHT-preAD study is to investigate the earliest preclinical stages of $\mathrm{AD}$ through intermediate to later stages until conversion to first cognitive symptoms, using clinical measures and biomarkers associated with cognitive progression. Previous publications describe the cohort and its clinical and neuropsychological features. ${ }^{19,20}$

Briefly, the INSIGHT-preAD study includes, at baseline, 318 cognitively normal white individuals from the Paris area, between 70 and 85 years of age, with subjective memory complaints and defined brain amyloid status, measured by $\mathrm{A} \beta$-PET, performed at baseline visit as mandatory inclusion criterion. Demographic data, clinical data, and $A P O E$ genotype have been collected at the point of the study inclusion. ${ }^{19}$ Exclusion criteria were history of neurologic or psychiatric diseases, including depressive disorders.

We selected all the individuals who underwent baseline and 24-month follow-up MRI assessment $(\mathrm{n}=276)$. Within this subsample, 4 participants converted to $\mathrm{AD}$ dementia diagnosis after 24 months and 1 participant after 36 months, one to primary progressive aphasia after 36 months and 1 to Lewy body dementia after 48 months.

\section{Standard protocol approvals, registrations, and patient consents}

The study was conducted in accordance with the tenets of the Declaration of Helsinki of 1975 and approved by the local institutional review board at the participating center. All participants or their representatives gave written informed consent for use of their clinical data for research purposes.

\section{Blood sampling and collection tube storage}

Blood samples were taken in the morning, after a 12-hour fast, handled in a standardized way, and centrifuged for 15 minutes at $2,000 \mathrm{~g}$ force at $4^{\circ} \mathrm{C}$. Per sample, plasma fraction was collected, homogenized, aliquoted into multiple $0.5 \mathrm{~mL}$ cryovialsterilized tubes, and finally stored at $-80^{\circ} \mathrm{C}$ within 2 hours from collection.

\section{Immunoassays for t-tau and NfL plasma biomarkers}

The Clinical Neurochemistry Laboratory, Sahlgrenska University Hospital, Sweden, performed the analyses of plasma t-tau and NfL concentrations. The measurements of each biomarker were performed in one round of experiments, using the same batch of reagents, by board-certified laboratory technicians who were blinded to the clinical data.

Plasma t-tau was measured using the Human Total Tau 2.0 kit on the Simoa platform (Quanterix, Lexington, MA). For 
plasma t-tau, both repeatability and intermediate precision was $12.2 \%$ for an internal quality control (QC) plasma sample with a concentration of $1.9 \mathrm{pg} / \mathrm{mL}^{21}$ Plasma NfL was measured using an in-house Simoa method, as previously described in detail. $^{22}$ Repeatability was $9.6 \%$ and $10.6 \%$ and intermediate precision $14.6 \%$ and $11.6 \%$, for 2 internal QC plasma samples with concentrations of 12.9 and $107 \mathrm{pg} / \mathrm{mL}^{21}$

\section{MRI acquisition}

Brain MRI acquisitions were conducted using a 3T MRI scanner (Siemens Magnetom Verio, Siemens Medical Solutions, Erlangen, Germany). The scanner had a quadrature detection head coil with 12 channels. High-resolution T1weighted structural MRI scans for the measurement of BFCS volume were acquired using a $3 \mathrm{D}$ TurboFLASH sequence with the following measures: orientation sagittal; repetition time 2,300 ms; echo time $2.98 \mathrm{~ms}$; inversion time $900 \mathrm{~ms}$; flip angle $9^{\circ}$; 176 slices; slice thickness $1 \mathrm{~mm}$; acquisition matrix $256^{*} 240$.

\section{MRI processing}

Processing steps and computational analyses followed the longitudinal processing stream implemented in statistical parametric mapping (SPM12; Wellcome Trust Center for Neuroimaging, London, UK) and CAT12 (dbm.neuro.unijena.de/cat/), adapted to the analysis of serial MRI scans used for the BFCS volume. ${ }^{23,24}$

BFCS mask was obtained on combined postmortem MRI and histology of an autopsy brain and has been described in detail elsewhere. ${ }^{11}$ Mesulam nomenclature was the reference for the histologic delineation of the BFCS and its subregions. ${ }^{25,26}$ The BFCS is separated into 4 principal groups of cholinergic cells: $\mathrm{Ch} 1$ and $\mathrm{Ch} 2$ (cholinergic cells associated with the medial septal nucleus and the vertical limb of the diagonal band of Broca $[\mathrm{Ch} 1 / 2]$ ), Ch3 (horizontal limb of the diagonal band of Broca), and Ch4 (cholinergic cells of the nucleus basalis of Meynert) ${ }^{26}$ (figure 1). The nucleus basalis of Meynert is the largest cholinergic nucleus of the BFCS and can be considered as the sum of its subdivisions: anterior to intermediate, anterior lateral/nucleus subputaminalis, and posterior subregions.

Volumes of the total BFCS and its subnuclei were corrected to the total intracranial volume (TIV) using the residuals method. First, a linear regression of the volume of a neuroanatomical structure on the TIV was fitted on the entire dataset. From the fitted model, the residuals, which reflect the differences between actual volume and fitted volume based on a participant's TIV, were calculated. ${ }^{27}$ The TIV-corrected measurements were expressed as follows: Vol_adj $j_{i}=V_{o_{i}}-b\left(T_{I} V_{i}-\right.$ meanTIV $)$. Vol_adj $j_{i}$ is the TIV-adjusted volume of participant $i$, Vol is the original uncorrected volume of participant $i, b$ is the slope from the linear regression of Vol on TIV, TIV is the TIV for participant I, and mean TIV is the mean TIV across all participants.

\section{Amyloid PET scan acquisitions and processing}

Florbetapir-PET scans were acquired in a single session on a Philips (Best, the Netherlands) Gemini GXL CT-PET scanner $50( \pm 5)$ minutes after injection of approximately 370 $\mathrm{MBq}$ (333-407 MBq) of florbetapir. PET images were analyzed with the RACHEL pipeline developed by the CATI (catineuroimaging.com). Details on the amyloid PET processing, standard uptake value ratio (SUVR) calculation, and definition of SUVR thresholds have been described previously. ${ }^{20,28} \mathrm{~A}$ combination of the whole cerebellum and pons was used as a reference region. As threshold for amyloid positivity, we used SUVR values equal to or higher than $0.79 .^{28}$

\section{APOE genotype}

The 5Prime ArchivePure DNA purification system was used to extract the DNA from frozen blood samples of participants. The Sanger method was used for the detection of $A P O E$ genotyping. Exon 4 from the APOE gene holding the single nucleotide polymorphism related to the $\varepsilon 3 / \varepsilon 4$ alleles was amplified using PCR with the following primers: APOE sense, 5'-TAAGCTTGGCACGGCTGTCCAAGGA-3'; APOE antisense, 5' -ACAGAATTCGCCCCGGCCTGGTACAC-3’. For each sample, the reaction mixture $(50 \mu \mathrm{L})$ contained $200 \mathrm{ng}$ of genomic DNA, $10 \mu \mathrm{L}$ PCR Flexi buffer (5x), $3 \mu \mathrm{L} \mathrm{MgCl}_{2}$ (25 mM), $1 \mu \mathrm{L}$ dNTPs $(10 \mathrm{mM}), 1 \mu \mathrm{L}$ of each forward and reverse primer $(10 \mu \mathrm{M})$, and $0.25 \mu \mathrm{L}$ GO Taq DNA polymerase (Promega, Madison, WI). The cycling program was carried out after a preheating step at $95^{\circ} \mathrm{C}$ for 2 minutes and 35 cycles of denaturation at $95^{\circ} \mathrm{C}$ for 1 minute, annealing at $68^{\circ} \mathrm{C}$ for 1 minute, and extension at $72^{\circ} \mathrm{C}$ for 1 minute. The amplified fragments were then purified and sequenced using the same primers. Participants were divided into 3 groups based on the $A P O E$ status: individuals carrying at least 1 APOE $\varepsilon 4$ allele (genotype $\varepsilon 4 / \varepsilon 4$ and $\varepsilon 4 / \varepsilon 3$ ) were classified as APOE $\varepsilon 4$ carriers ( $A P O E \varepsilon 4+$ ); individuals carrying an $A P O E$ \&2 allele (genotype $\varepsilon 2 / \varepsilon 2$ and $\varepsilon 2 / \varepsilon 3$ ) were classified as APOE $\varepsilon 2$ carriers ( $A P O E \varepsilon 2+)$; and the others as $A P O E \varepsilon 3 / \varepsilon 3$ genotype.

\section{Statistical analysis}

Annualized percentage change (APC) of the adjusted volume of the BFCS and its subnuclei was computed as follows:

$$
\mathrm{APC}=\frac{\text { change from baseline }}{\text { value at baseline }} \times \frac{365}{\text { MRI delay }} \times 100
$$

Multiple linear models including age, sex, education, amyloid status, and APOE status as covariates as well as t-tau concentration, NfL, and the interactions between NfL and t-tau were performed to investigate their effect on the APC of the BFCS and its subnuclei. Benjamini-Hochberg correction was performed to handle the multiple testing in the analysis of the BFCS subnuclei. Type II F-tests were used to test main effects and interactions. Cohen $\mathrm{f} 2$ was calculated to assess effect sizes.

Normality of residuals and homoscedasticity were checked visually. Cook distances were calculated to identify the participants who change most the fit of the model (i.e., influential data or influencers). ${ }^{29}$ The Cook distance of 1 participant is defined as the sum of the other participants' differences 


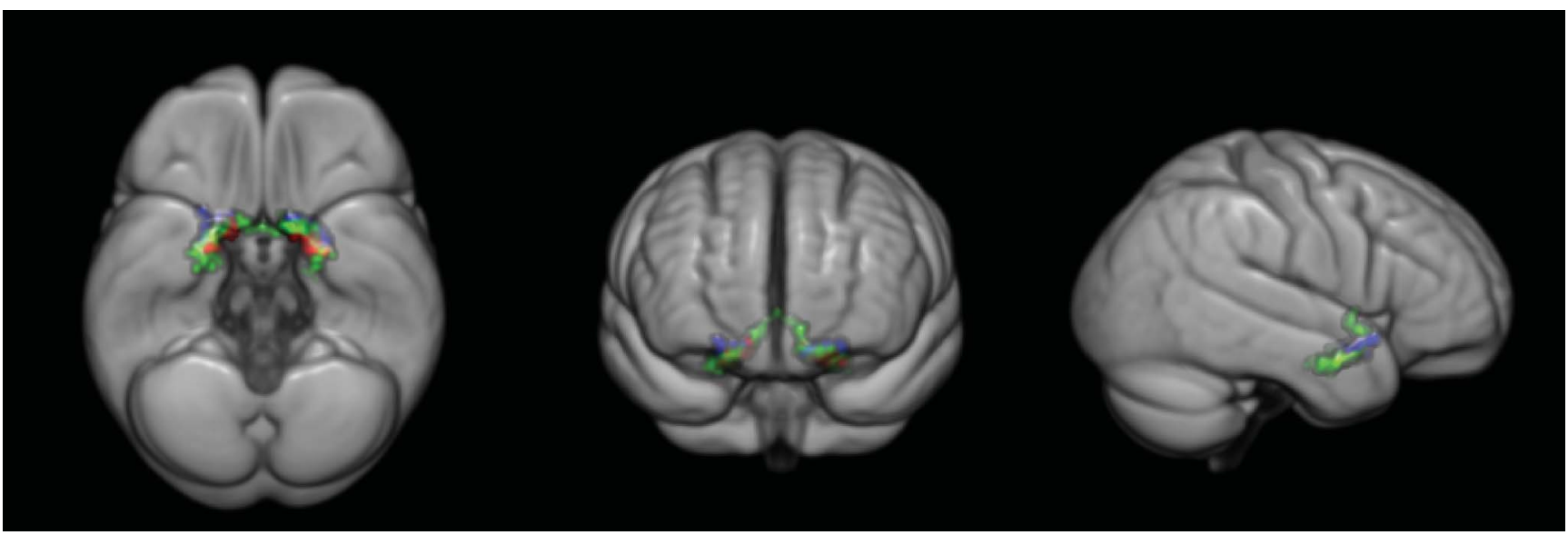

Red represents the Ch1-2 regions of interest corresponding to the medial septum and vertical limb of the diagonal band of Broca, blue is the horizontal limb of the diagonal band of Broca (not selected as a region of interest in the current article), green represents the Ch4 region of interest corresponding to the nucleus basalis of Meynert. Regions of interest have been superimposed on the render representation of the T1-weighted high-resolution ICBM 2009a nonlinear asymmetric Montreal Neurological Institute 152 standard space template. Further details regarding the subregional delineation of basal forebrain cholinergic system are reported in reference 11.

between their fitted value from the model with the participant and the fitted value from the model without this participant. ${ }^{29}$

The effect of influencers in the model was examined by removing from the model any points with large Cook distances ( $>4 / n$, where $n$ is the number of observations). ${ }^{30}$ Statistical analyses were performed using $\mathrm{R}$ 3.3.2.

\section{Data availability}

Anonymized data not published within this article will be made available by request from any qualified investigator after evaluation of the request by the INSIGHT-preAD Scientific Committee.

\section{Results}

Table 1 describes sociodemographic features, global cognitive performances, the frequencies of $A P O E$ \&P allele, as well as the concentration of blood-based biomarkers and BFCS volume at baseline in the INSIGHT-preAD participants. Seventythree percent of individuals in our cohort were amyloidnegative while $23 \%$ were amyloid-positive at baseline.

\section{Baseline plasma t-tau and NfL levels as predictors of atrophy rates of the BFCS and its subnuclei}

Higher plasma t-tau concentrations were associated with increased rate of atrophy of the BFCS ( $p=0.025$, table 2$)$. NfL did not predict BFCS-APC $(p=0.753$, table 2$)$. This finding was checked for robustness by removing from the model the influencer individuals $(\mathrm{n}=19)$ with Cook distances greater than 0.014 (figure 2B). As for the model including influencers, in the model without influencers only t-tau predicted an increased rate of BFCS atrophy ( $p=0.031$, table 2 and figure $2 \mathrm{~A})$.
Considering the subnuclei of the BFCS, the model with influencers showed a significant effect of $\mathrm{t}$-tau in predicting the rate of atrophy of the anterior $(\mathrm{Ch} 1 / 2)(p=0.026$; $p$ corrected $=0.026$, table 3$)$ and posterior (Ch4) sectors of the BFCS ( $p=$ $0.021 ; p$ corrected $=0.026$, table 3 ). This finding was checked for robustness by removing from the model the influencer individuals with Cook distances greater than 0.014 (figures $3 \mathrm{~B}$ and 4B). The model without influencers reported a similar effect of $\mathrm{t}$-tau in predicting higher rates of atrophy in the $\mathrm{Ch} 1 / 2$ and $\mathrm{Ch} 4$ sectors of the BFCS (table 3 and figures 3A and 4A).

The interaction between plasma t-tau and NfL concentrations was not associated with atrophy rates of the whole BFCS or its subsectors (Ch1/2 and $\mathrm{Ch} 4)$. Neither APOE genotype nor amyloid status had a significant effect on predicting atrophy rates of the BFCS or its $\mathrm{Ch} 1 / 2$ and $\mathrm{Ch} 4$ sectors, either in the model with or without influencers (tables 2 and 3 ). In contrast, sex displayed a significant effect in predicting the rate of atrophy of the nucleus basalis of Meynert (Ch4) in the model without influencers $(p$ value $=0.007$; corrected $p=0.014$, table 3).

\section{Discussion}

We assessed the association between baseline plasma t-tau and NfL concentrations and the BFCS rate of atrophy, a potential proxy of BFCS neurodegeneration, in a cohort of cognitively intact older adults with subjective memory complaints.

Our results show that higher baseline plasma t-tau concentrations are significantly correlated with an increased rate of BFCS atrophy. In particular, both the anterior $(\mathrm{Ch} 1 / 2)$ and posterior (Ch4) sectors of the BFCS are affected by elevated baseline t-tau concentrations. 
Table 1 Sociodemographic, global cognition, and genetic risk factors as well as baseline concentrations of plasma and neuroimaging markers in the INSIGHT-preAD participants with both baseline and 24 months assessment

Values (total $\mathbf{n}=\mathbf{2 7 6})$

\begin{tabular}{|c|c|}
\hline & Values (total $n=276$ ) \\
\hline Age at baseline, y & $75.7 \pm 3.4$ \\
\hline \multicolumn{2}{|l|}{ Education } \\
\hline High & $192(69)$ \\
\hline Low & $84(31)$ \\
\hline \multicolumn{2}{|l|}{ Sex } \\
\hline Men & $106(38)$ \\
\hline Women & $170(61)$ \\
\hline MMSE at baseline & $28.4 \pm 0.9$ \\
\hline \multicolumn{2}{|l|}{ APOE $\varepsilon 4$ carriers } \\
\hline Carriers & $55(20)$ \\
\hline Not carriers & $221(80)$ \\
\hline \multicolumn{2}{|l|}{ Amyloid PET } \\
\hline- & $203(73)$ \\
\hline+ & $73(26)$ \\
\hline Baseline plasma t-tau & $4.5 \pm 2.5$ \\
\hline Baseline plasma NfL & $29.4 \pm 12.5$ \\
\hline Baseline adjusted BFCS volume, $\mathrm{mm}^{3}$ & $664.2 \pm 43.3$ \\
\hline
\end{tabular}

Abbreviations: BFCS = basal forebrain cholinergic system; INSIGHT-preAD = Investigation of Alzheimer's Predictors in Subjective Memory Complainers; MMSE = Mini-Mental State Examination; NfL = neurofilament light; t-tau = total tau. Variables are $n(\%)$ or mean \pm SD. Education was determined according to an 8point scale converted into a dichotomous variable: individuals with a score lower than or equal than 5 were considered low educated, while individuals with a score higher than 5 (high school graduate) were considered highly educated.

On the other hand, no correlation was found between baseline plasma NfL concentrations and the rate of atrophy of the anterior or posterior sectors of the BFCS. There was no significant interaction between plasma t-tau and NfL concentrations on BFCS rate of atrophy either. No significant effects of brain amyloid load or $A P O E$ genotype on the annual rate of atrophy of the whole BFCS, Ch4, or Ch1/2 sectors were found.

In the last 10 years, several human studies reported increased in vivo concentrations of both $\mathrm{NfL}$ and $\mathrm{t}$-tau in body fluids, such as blood and CSF, across different pathophysiologic conditions, including traumatic brain injury (TBI), peripheral neuropathies, multiple sclerosis, and neurodegenerative diseases, including atypical parkinsonian disorders and $\mathrm{AD} .{ }^{31-34}$

Tau is an axonal protein physiologically and directly involved in microtubule assembly and cytoskeletal stability.

The BFCS represents one of the first brain structures affected by $\mathrm{AD}$ pathophysiology. ${ }^{35}$ Human postmortem studies showed that BFCS cortical projections are composed of unmyelinated axons. $^{3-5}$ Recent studies conducted in TBI cohorts or using brain tissue of patients with $\mathrm{AD}$ suggested that damage of unmyelinated fibers may express more an increase of tau than NfL concentrations in biofluids, while damage of myelinated large caliber axons both express tau and NfL concentrations in biofluids. ${ }^{31,36-38}$ Based on this evidence, the association found between the BFCS and plasma tau in our population at risk of $\mathrm{AD}$ may more likely reflect damage of unmyelinated axons. We encourage future longitudinal studies in preclinical cohorts of $\mathrm{AD}$ to corroborate whether plasma tau can reflect the presence of axonal damage in a key brain region implicated in early stages of $\mathrm{AD}$ such as the BFCS. If so, these results may pave the path toward the validation of a reliable blood-based marker to monitor tau pathology in the BFCS leading to the progression of neurodegenerative alterations in early stages of $\mathrm{AD}$.

Previous studies reported an increase of plasma t-tau concentrations in individuals with $\mathrm{MCI}$ due to $\mathrm{AD}$ and $\mathrm{AD}$ dementia compared with controls. ${ }^{39-42}$ In a meta-analysis investigating 231 articles including 15,699 patients with $\mathrm{AD}$ and 13,018 controls, plasma t-tau was the only biomarker discriminating patients with $\mathrm{AD}$ from controls (average ratio of levels in patients with $\mathrm{AD}$ vs controls: $1.95,95 \%$ confidence interval $1.12-3.38, p=0.02) .{ }^{21}$ In patients with $\mathrm{AD}$ and healthy controls, high plasma t-tau was associated with high CSF t-tau concentrations and low CSF $A \beta_{1-42}$ peptide levels. ${ }^{14}$ Interestingly, both cross-sectional and longitudinal studies showed correlations between high baseline concentrations of plasma t-tau and structural neuroimaging markers of $\mathrm{AD} \cdot{ }^{14,41-43}$ At baseline, negative correlations between plasma $\mathrm{t}$-tau concentrations and volumes of the hippocampus, amygdala, ${ }^{41}$ precuneus, ${ }^{43}$ and abnormal cortical thickness in $\mathrm{AD}$ signature regions ${ }^{42}$ were reported. In longitudinal studies, baseline concentration of plasma t-tau predicted faster increase of ventricular volume, accelerated decrease of hippocampal volume, and accelerated regional brain glucose hypometabolism. ${ }^{14}$ None of these studies investigated the predictive effect of plasma t-tau concentration on BFCS rate of atrophy.

Our results indicate a potential role of plasma t-tau as a peripheral biomarker of BFCS tissue injury in a population of cognitively intact older adults, including (amyloid-positive) individuals with preclinical $\mathrm{AD}$ pathophysiology. These results are in line with postmortem findings showing that the BFCS is one of the earliest and most vulnerable brain structures to neurofibrillary degeneration. ${ }^{1,44}$

On the other hand, studies on plasma NfL, a structural protein presenting high concentrations in the large-caliber myelinated subcortical axons of the white matter (WM), ${ }^{45}$ also showed increased plasma $\mathrm{NfL}$ in patients with $\mathrm{AD}$ compared to controls, with a receiver operating characteristic area under the curve value of $0.87 .{ }^{15}$ Recently, plasma NfL dynamics in serum predicted disease progression and brain neurodegeneration at the early presymptomatic stages of familial 
Table 2 Correlation of plasma total tau (t-tau) and neurofilament light (NfL) concentrations with progression of basal forebrain cholinergic system (BFCS) atrophy

\begin{tabular}{|c|c|c|c|c|c|c|c|c|c|c|c|c|}
\hline \multirow[b]{2}{*}{ APC } & \multicolumn{6}{|c|}{ Model with influencers } & \multicolumn{6}{|c|}{ Model without influencers } \\
\hline & $\mathbf{N}$ & Estimate & SE & F value & $p$ Value $^{a}$ & $f^{2}$ & $\mathbf{N}$ & Estimate & SE & F value & $p$ Value $^{a}$ & $f^{2}$ \\
\hline BFCS & 270 & & & & & & 251 & & & & & \\
\hline Intercept & & -0.48 & 0.69 & - & - & - & & -0.43 & 0.59 & - & - & - \\
\hline t-tau & & -0.01 & 0.02 & 5.0675 & 0.025 & 0.019 & & -0.01 & 0.02 & 4.6815 & 0.031 & 0.019 \\
\hline NFL & & 0.002 & 0.003 & 0.0990 & 0.753 & 0.000 & & 0.001 & 0.004 & 0.0070 & 0.933 & 0.000 \\
\hline t-tau*NFL & & -0.0003 & 0.0006 & 0.3618 & 0.548 & 0.001 & & -0.0003 & -0.0007 & 0.2440 & 0.621 & 0.001 \\
\hline Age & & 0.004 & 0.009 & 0.2563 & 0.613 & 0.001 & & 0.004 & 0.007 & 0.3600 & 0.549 & 0.001 \\
\hline Sex & & -0.01 & 0.06 & 0.0444 & 0.833 & 0.000 & & -0.03 & 0.05 & 0.3733 & 0.541 & 0.002 \\
\hline Education & & -0.03 & 0.06 & 0.3494 & 0.554 & 0.001 & & -0.05 & 0.05 & 0.9204 & 0.338 & 0.004 \\
\hline Amyloid status & & 0.02 & 0.07 & 0.1457 & 0.703 & 0.001 & & -0.009 & 0.05 & 0.0247 & 0.875 & 0.000 \\
\hline APOE genotype & & -0.15 & 0.11 & 0.9600 & 0.384 & 0.007 & & -0.14 & 0.09 & 1.0821 & 0.340 & 0.009 \\
\hline
\end{tabular}

Abbreviations: APC = annual percent change; $f^{2}=\operatorname{Cohen} f^{2}$ value for each measure in the model

a $p$ Values corrected for age, education, sex, amyloid status, and APOE genotype.

AD. ${ }^{46}$ High plasma NfL concentrations were further associated with accelerated decline in hippocampal volume and cortical thickness in $\mathrm{AD}$ signature regions, ventricle enlargement, and brain hypometabolism in a sample covering participants with $\mathrm{MCI}$ and $\mathrm{AD}$ dementia, as well as cognitively intact older individuals. ${ }^{15}$ In contrast, as observed in our study, Pereira and colleagues ${ }^{47}$ did not find any significant correlation between plasma NfL and regional cortical thinning in a sample of cognitively intact older adults (both amyloid-positive and amyloid-negative). However, significant correlations were found in MCI amyloid-negative, MCI amyloid-positive, and $\mathrm{AD}$ amyloid-positive cases, ${ }^{47}$ suggesting that plasma NfL may represent a marker of neuronal injury at later stages of neurodegeneration.

Recent studies showed increased NfL concentrations both in serum and CSF of individuals with a medical history of repeated head concussions, such as professional athletes and amateur boxers, compared to individuals with no history of the same typology of repeated brain trauma. ${ }^{48,49}$ These findings highlighted the increase of NfL concentrations in body fluids as a consequence of the axonal damage in WM large-caliber myelinated fibers.

Individuals with a medical history of repetitive mild TBI showed significantly increased concentrations of NfL but not of $\mathrm{t}$-tau. ${ }^{36}$ This result led the authors to assume that short unmyelinated axons are not substantially damaged after repetitive mild TBI. ${ }^{36}$ With respect to our current results, this finding may support the hypothesis that significantly increased NfL concentrations, representing damage of WM large-caliber myelinated fibers, may only be detected at later stages of neurodegeneration. This hypothesis would also be consistent with the anatomy of the BFCS neurons (especially the $\mathrm{Ch} 4$ portion), which are mainly characterized by unmyelinated cortical axons projecting to the cortical mantle through the underlying WM. ${ }^{5}$

Neuropathologic studies have shown that earliest $\mathrm{t}$-tau posttranslational modifications are found in the BFCS compared to other brain regions, suggesting that $\mathrm{t}$-tau post-translational modifications within the BFCS represent an initial neurodegenerative mechanism related to $\mathrm{AD} .^{35}$

Our results are also in line with previous findings reporting an association between elevated plasma t-tau concentrations and cognitive decline, independently of brain amyloid load. ${ }^{13}$ This suggests that plasma $\mathrm{t}$-tau concentrations might be useful as a surrogate biomarker for cognitive decline or neurodegeneration of the BFCS, but not as a pathognomonic $\mathrm{AD}$ specific biomarker.

Our study has some limitations, such as the lack of a sufficient number of individuals with a clinical diagnosis of $\mathrm{AD}$ or other neurodegenerative diseases, which prevented us from testing plasma t-tau and NfL concentrations for clinical disease specificity and their association with BFCS rate of atrophy. However, associations between plasma t-tau levels and BFCS atrophy rates were independent of amyloid status, thus suggesting little specificity for $\mathrm{AD}$ over other neurodegenerative processes.

Moreover, since our data only included relatively old individuals as defined by the inclusion criteria of the INSIGHTpreAD cohort, it might be of interest to investigate the predictive effect of plasma $\mathrm{t}$-tau and $\mathrm{NfL}$ concentrations on BFCS rate of atrophy across a broader age range. 
Figure 2 Correlation of plasma total tau (t-tau) and basal forebrain cholinergic system (BFCS) rates of atrophy over time
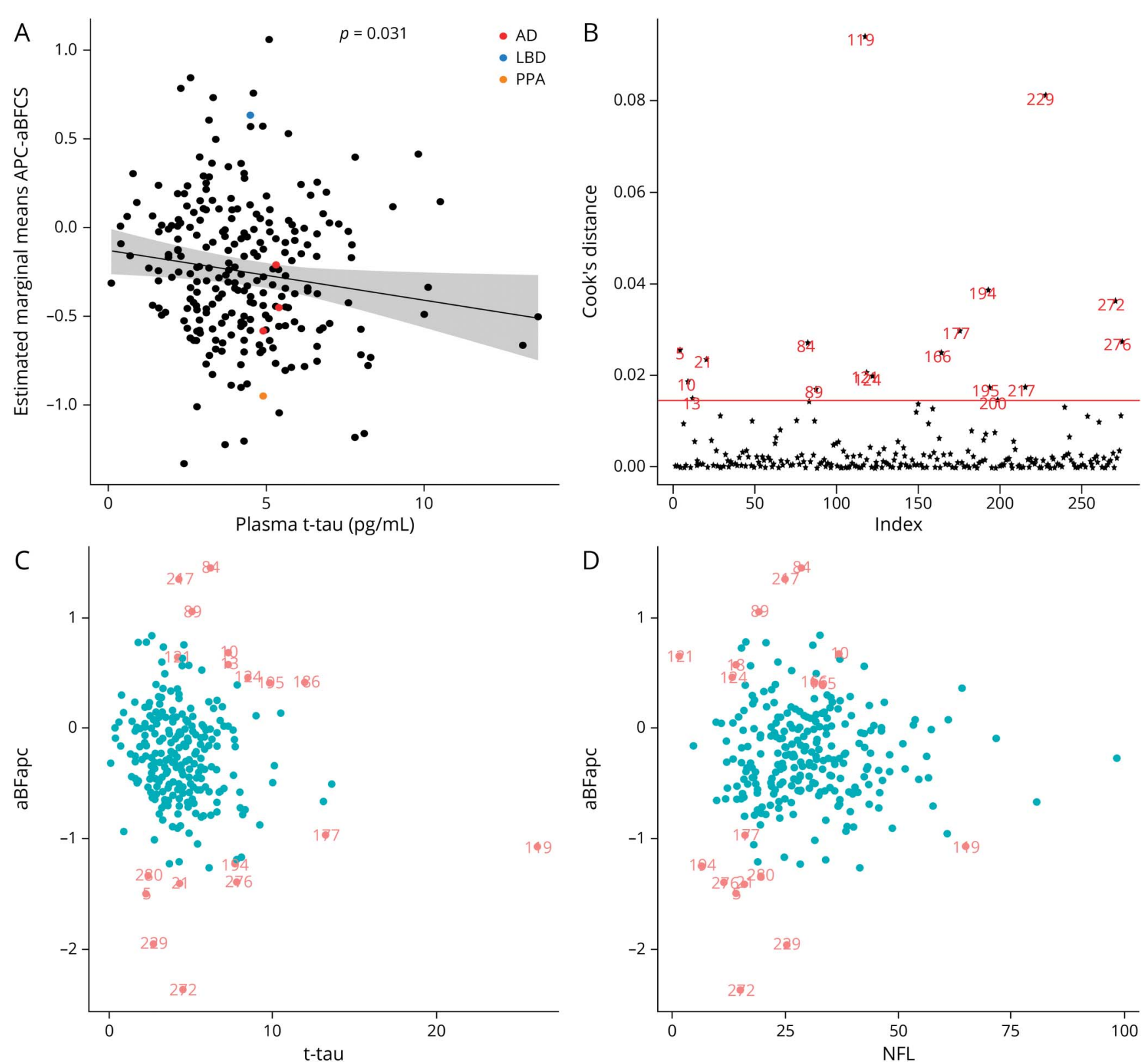

(A) Model without influencers. Two patients with Alzheimer disease (AD) were influencers; therefore, they have been removed from the model without influencers. (B) Cook distance as measure of influence for each participant from the linear regression on BFCS annual percent change (APC). (C, D) The distribution of influencers (red points) in relation to the association between the adjusted BFCS (aBFCS) APC and t-tau (C) or neurofilament light (NfL) (D) concentrations. Red numbers denote influential observations by the Cook distance. $\mathrm{aBFapc}=$ adjusted basal forebrain annual percent change; $\mathrm{LBD}=\mathrm{Lewy}$ body dementia; PPA = primary progressive aphasia.

Finally, the volumetric BFCS measurement is only an indirect marker of cholinergic system integrity. The delineation of BFCS was determined based on stereotactic mapping of the forebrain's cholinergic nuclei using combined histology and postmortem MRI. ${ }^{11}$ Nevertheless, we cannot exclude that the measurement of the BFCS may also refer to change in neuronal populations that are not exclusively cholinergic.

Our results show that an elevated baseline concentration of plasma t-tau is associated with a higher rate of atrophy of the anterior and posterior BFCS in cognitively intact older adults at risk for $\mathrm{AD}$. These results were independent of brain amyloid status and $A P O E$ genotype. In contrast, no association was found between baseline plasma NfL concentrations and BFCS rate of atrophy. These findings suggest that plasma t-tau, but not NfL, might reflect the neurodegeneration processes in the BFCS in a population of older adults at risk for $\mathrm{AD}$. This is in line with neuropathologic findings showing tau-mediated alterations in the unmyelinated cortical axons of the BFCS in early stages of $\mathrm{AD}$. 
Table 3 Correlation of plasma total tau (t-tau) and neurofilament light (NfL) concentrations with progression of basal forebrain cholinergic system (BFCS) subnuclei atrophy

\begin{tabular}{|c|c|c|c|c|c|c|c|c|c|c|c|c|c|c|}
\hline & With & luencers & & & & & & With & influencer & & & & & \\
\hline APC & $\mathbf{N}$ & Estimate & SE & F value & $p$ Value $^{a}$ & $p$ Value corr ${ }^{b}$ & $f^{2}$ & $\mathbf{N}$ & Estimate & SE & F value & $p$ Value $^{a}$ & $p$ Value corr ${ }^{b}$ & $f^{2}$ \\
\hline Ch4 & 270 & & & & & & & 253 & & & & & & \\
\hline Intercept & & -0.72 & 0.72 & - & - & - & - & & -1.01 & 0.61 & - & - & - & - \\
\hline t-tau & & -0.01 & 0.02 & 5.3333 & 0.021 & 0.026 & 0.020 & & -0.01 & 0.02 & 4.9090 & 0.026 & 0.047 & 0.020 \\
\hline NFL & & 0.002 & 0.004 & 0.0686 & 0.793 & 0.793 & 0.000 & & 0.0006 & 0.004 & 0.4803 & 0.488 & 0.742 & 0.002 \\
\hline t-tau*NFL & & -0.0004 & 0.0006 & 0.4383 & 0.508 & 0.508 & 0.002 & & -0.0004 & -0.0007 & 0.3604 & 0.548 & 0.548 & 0.001 \\
\hline Age & & 0.007 & 0.009 & 0.5681 & 0.451 & 0.841 & 0.002 & & 0.01 & 0.008 & 2.3651 & 0.125 & 0.250 & 0.010 \\
\hline Sex & & -0.11 & 0.06 & 3.2114 & 0.074 & 0.148 & 0.012 & & -0.14 & 0.05 & 7.2946 & 0.007 & 0.014 & 0.030 \\
\hline Education & & -0.02 & 0.06 & 0.0930 & 0.760 & 0.760 & 0.000 & & -0.005 & 0.05 & 0.0087 & 0.925 & 0.925 & 0.000 \\
\hline Amyloid status & & 0.01 & 0.07 & 0.0405 & 0.840 & 0.919 & 0.000 & & -0.03 & 0.06 & 0.2988 & 0.585 & 0.648 & 0.001 \\
\hline APOE genotype & & -0.16 & 0.11 & 0.9777 & 0.377 & 0.567 & 0.006 & & -0.16 & 0.09 & 1.3809 & 0.253 & 0.409 & 0.010 \\
\hline Ch1/2 & 270 & & & & & & & 256 & & & & & & \\
\hline Intercept & & -0.02 & 0.86 & - & - & - & - & & -0.10 & 0.77 & - & - & - & - \\
\hline t-tau & & -0.009 & 0.03 & 4.9759 & 0.026 & 0.027 & 0.019 & & -0.008 & 0.03 & 3.9535 & 0.047 & 0.047 & 0.016 \\
\hline NFL & & 0.006 & 0.004 & 1.4216 & 0.234 & 0.468 & 0.005 & & 0.004 & 0.005 & 0.1085 & 0.742 & 0.742 & 0.000 \\
\hline $\mathrm{t}$-tau*NFL & & -0.0005 & 0.0007 & 0.6376 & 0.425 & 0.508 & 0.002 & & -0.0006 & 0.0009 & 0.5181 & 0.472 & 0.548 & 0.002 \\
\hline Age & & 0.002 & 0.01 & 0.0400 & 0.841 & 0.841 & 0.000 & & 0.005 & 0.010 & 0.2483 & 0.618 & 0.618 & 0.001 \\
\hline Sex & & -0.04 & 0.07 & 0.3526 & 0.553 & 0.553 & 0.001 & & -0.04 & 0.06 & 0.4171 & 0.518 & 0.518 & 0.002 \\
\hline Education & & -0.07 & 0.08 & 0.7479 & 0.387 & 0.760 & 0.003 & & -0.04 & 0.07 & 0.3906 & 0.532 & 0.925 & $f^{2}$ \\
\hline Amyloid status & & -0.008 & 0.08 & 0.0104 & 0.919 & 0.919 & 0.000 & & -0.03 & 0.07 & 0.2077 & 0.648 & 0.648 & \\
\hline APOE genotype & & -0.14 & 0.13 & 0.5671 & 0.567 & 0.567 & 0.004 & & -0.15 & 0.12 & 0.8956 & 0.409 & 0.409 & - \\
\hline
\end{tabular}

Abbreviations: APC = annual percent change; Ch4 = nucleus basalis of Meynert; Ch1/2 $=$ Ch1 and Ch2 sectors; $f^{2}=$ Cohen $f^{2}$ values for each measure in the model.

a $p$ Values adjusted for age, education, sex, amyloid status, and APOE genotype. 

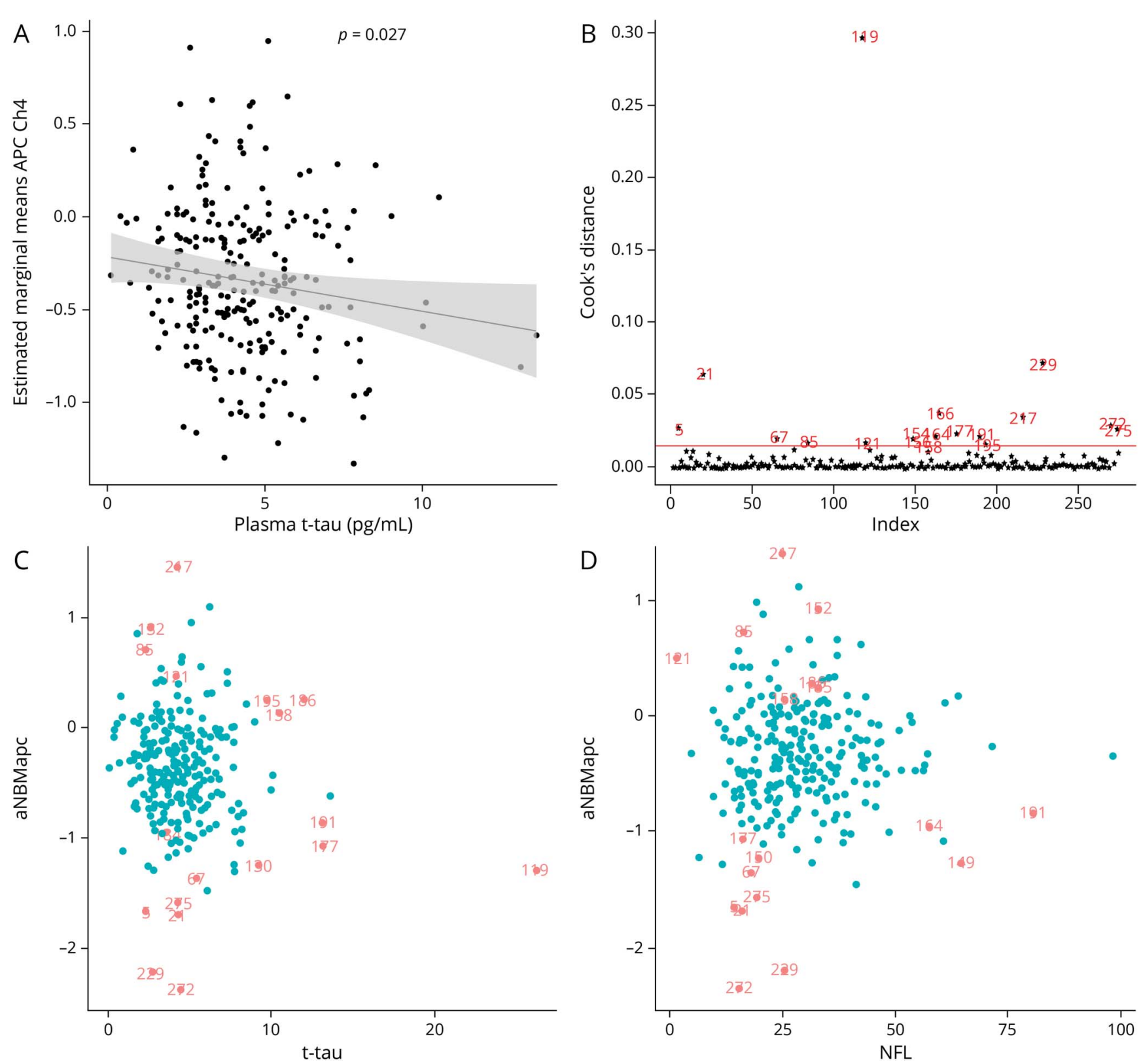

(A) Model without influencers. (B) Cook distance as measure of influence for each participant from the linear regression on annual percent change (APC) of Ch4. (C, D) The distribution of influencers (red points) in relation to the association between the APC of Ch4 and t-tau (C) or neurofilament light (NfL) (D) concentrations. Red numbers denote influential observations by Cook distance. aNBMapc = adjusted nucleus basalis annual percent change.

To our knowledge, this is the first study investigating the association between candidate markers of neurodegeneration in the plasma and in vivo atrophy rates of the BFCS, a brain region affected early by AD.

Based on the current knowledge of $\mathrm{AD}$-related neuropathology, ${ }^{35}$ the anatomical features of the basal forebrain, and the existing literature on the alterations of the 2 plasma markers in cognitively normal individuals, ${ }^{36}$ we hypothesize that plasma $\mathrm{t}$-tau and plasma NfL concentrations may reflect anatomically different processes at different time points in the pathophysiologic course of $\mathrm{AD}$. Thus, plasma t-tau may be useful in detecting early neurodegenerative processes of the BFCS, and other brain structures, that are characterized by unmyelinated cortical axons, whereas plasma NfL may be more closely associated with neurodegenerative processes characterized by damage of WM large-caliber myelinated fibers that occur at later disease stages in $\mathrm{AD}$. Additional studies on molecular NfL and tau mechanisms and populations including different clinical stages of $\mathrm{AD}$ are needed to confirm this hypothesis.

\section{Study funding}

The study was promoted by INSERM in collaboration with ICM, IHU-A-ICM, and Pfizer and received support within the Investissement d'Avenir (Agence Nationale de la Recherche-10-IA Agence Institut Hospitalo-Universitaire-6 [ANR-10-AIHU-06]) 

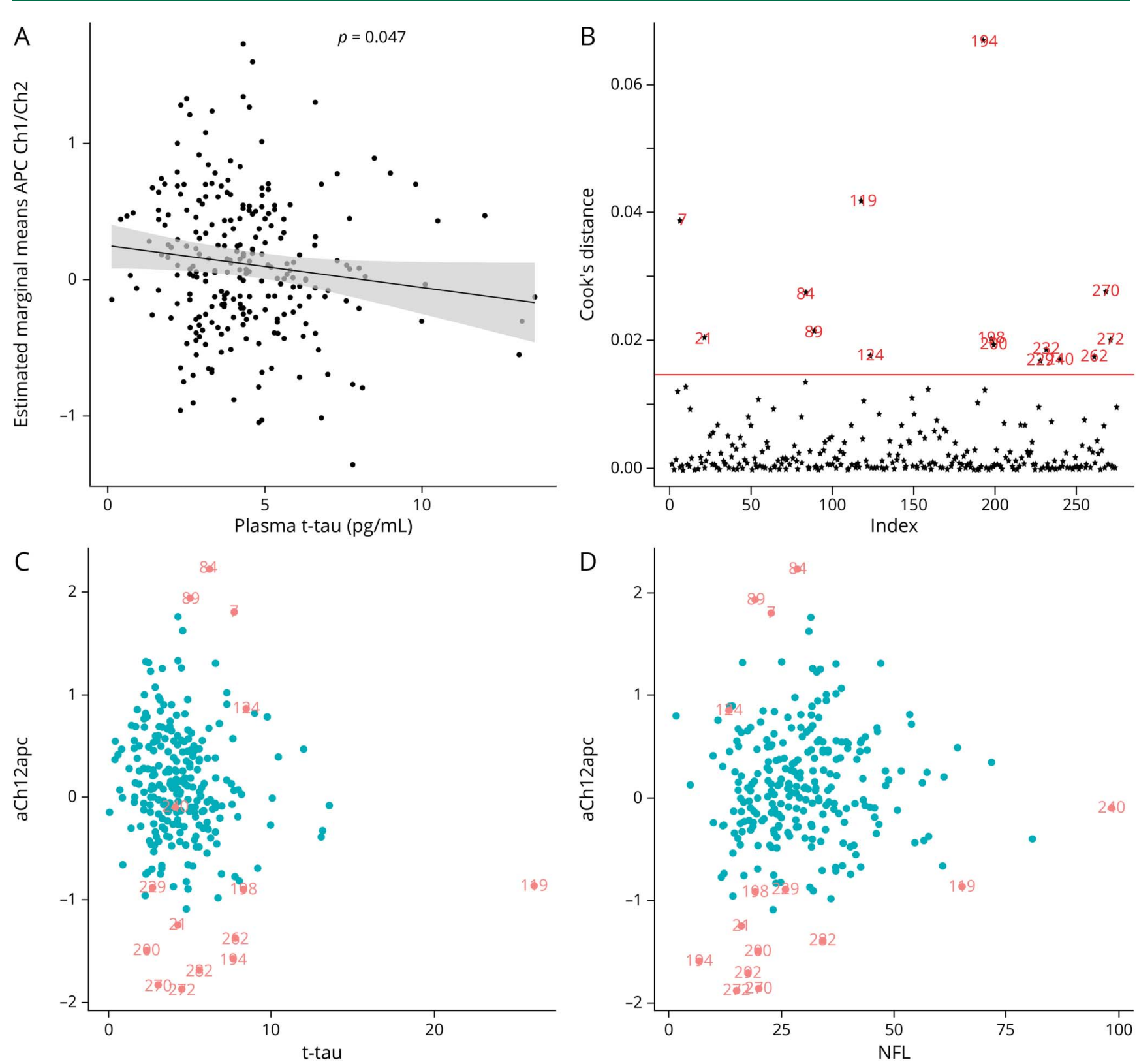

(A) Model without influencers. (B) Cook distance as measure of influence for each participant from the linear regression on annual percent change (APC) of Ch1/2. (C, D) The distribution of influencers (red points) in relation to the association between the APC of Ch1/2 and t-tau (C) or neurofilament light (NfL) (D). Red numbers denote influential observations by Cook distance. aCh2apc = adjusted Ch2 annual percent change.

program. The study was promoted in collaboration with the $\mathrm{CHU}$ de Bordeaux (coordination CIC EC7), the promoter of Memento cohort, funded by the Foundation Plan-Alzheimer. The study was further supported by AVID/Lilly, the Program PHOENIX led by the Sorbonne University Foundation, and sponsored by la Fondation pour la Recherche sur Alzheimer. H.H. is an employee of Eisai Inc. During his previous work (until April 2019), he was supported by the AXA Research Fund, the Fondation partenariale Sorbonne Université and the Fondation pour la Recherche sur Alzheimer, Paris, France H.Z. is a Wallenberg Academy Fellow supported by grants from the Swedish Research Council, the European Research Council, Swedish State Support for Clinical
Research (ALFGBG), and the UK Dementia Research Institute at UCL. K.B. holds the Torsten Söderberg Professorship in Medicine at the Royal Swedish Academy of Sciences and is supported by the Swedish Research Council (\#2017-00915), the Swedish Alzheimer Foundation (\#AF-742881), Hjärnfonden, Sweden (\#FO20170243), and a grant (\#ALFGBG-715986) from the Swedish state under agreement between the Swedish government and the County Councils, the ALF-agreement.

\section{Disclosure}

E. Cavedo reports no disclosures relevant to the manuscript. S. Lista received lecture honoraria from Roche and Servier. 
M. Houot, M. Grothe, S. Teipel, H. Zetterberg, K. Blennow, M. Habert, M. Potier, and B. Dubois report no disclosures relevant to the manuscript. A. Vergallo received lecture honoraria from Roche, MagQu LLC, and Servier. H. Hampel is an employee of Eisai Inc. and serves as Senior Associate Editor for the Journal Alzheimer's \& Dementia; during the past three years he received lecture fees from Servier, Biogen and Roche, research grants from Pfizer, Avid, and MSD Avenir (paid to the institution), travel funding from Eisai, Functional Neuromodulation, Axovant, Eli Lilly and company, Takeda and Zinfandel, GEHealthcare and Oryzon Genomics, consultancy fees from Qynapse, Jung Diagnostics, Cytox Ltd., Axovant, Anavex, Takeda and Zinfandel, GE Healthcare, Oryzon Genomics, and Functional Neuromodulation, and participated in scientific advisory boards of Functional Neuromodulation, Axovant, Eisai, Eli Lilly and company, Cytox Ltd., GE Healthcare, Takeda and Zinfandel, Oryzon Genomics and Roche Diagnostics. H.H. is coinventor in the following patents as a scientific expert and has received no royalties: (1) In Vitro Multiparameter Determination Method for the Diagnosis and Early Diagnosis of Neurodegenerative Disorders (patent number: 8916388); (2) In Vitro Procedure for Diagnosis and Early Diagnosis of Neurodegenerative Diseases (patent number: 8298784); (3) Neurodegenerative Markers for Psychiatric Conditions (publication number: 20120196300); (4) In Vitro Multiparameter Determination Method for the Diagnosis and Early Diagnosis of Neurodegenerative Disorders (publication number: 20100062463); (5) In Vitro Method for the Diagnosis and Early Diagnosis of Neurodegenerative Disorders (publication number: 20100035286); (6) In Vitro Procedure for Diagnosis and Early Diagnosis of Neurodegenerative Diseases (publication number: 20090263822); (7) In Vitro Method for the Diagnosis of Neurodegenerative Diseases (patent number: 7547553); (8) CSF Diagnostic in Vitro Method for Diagnosis of Dementias and Neuroinflammatory Diseases (publication number: 20080206797); (9) In Vitro Method for the Diagnosis of Neurodegenerative Diseases (publication number: 20080199966); (10) Neurodegenerative Markers for Psychiatric Conditions (publication number: 20080131921). H.Z. has served on scientific advisory boards for Roche Diagnostics, Wave, Samumed, and CogRx and is a cofounder of Brain Biomarker Solutions in Gothenburg AB, a GU Ventures-based platform company at the University of Gothenburg. K.B. has served as a consultant or on advisory boards for Alzheon, CogRx, Biogen, Lilly, Novartis, and Roche Diagnostics, and is a cofounder of Brain Biomarker Solutions in Gothenburg AB, a GU Venture-based platform company at the University of Gothenburg. Go to Neurology.org/N for full disclosures.

\section{Publication history}

Received by Neurology February 13, 2019. Accepted in final form June 28, 2019.

\begin{tabular}{|c|c|c|c|}
\hline Name & Location & Role & Contribution \\
\hline $\begin{array}{l}\text { Enrica } \\
\text { Cavedo, } \\
\text { PhD }\end{array}$ & $\begin{array}{l}\text { Sorbonne } \\
\text { University, Paris }\end{array}$ & Author & $\begin{array}{l}\text { Designed and } \\
\text { conceptualized study, } \\
\text { analyzed the data, } \\
\text { interpreted the data, } \\
\text { drafted the manuscript for } \\
\text { intellectual content }\end{array}$ \\
\hline $\begin{array}{l}\text { Simone } \\
\text { Lista, PhD }\end{array}$ & $\begin{array}{l}\text { Sorbonne } \\
\text { University, Paris }\end{array}$ & Author & $\begin{array}{l}\text { Interpreted the data, } \\
\text { revised the manuscript for } \\
\text { intellectual content }\end{array}$ \\
\hline $\begin{array}{l}\text { Marion } \\
\text { Houot, MS }\end{array}$ & $\begin{array}{l}\text { Sorbonne } \\
\text { University, Paris }\end{array}$ & Author & $\begin{array}{l}\text { Analyzed the data, revised } \\
\text { the manuscript for } \\
\text { intellectual content }\end{array}$ \\
\hline $\begin{array}{l}\text { Andrea } \\
\text { Vergallo, } \\
\text { MD }\end{array}$ & $\begin{array}{l}\text { Sorbonne } \\
\text { University, Paris }\end{array}$ & Author & $\begin{array}{l}\text { Interpreted the data, } \\
\text { revised the manuscript for } \\
\text { intellectual content }\end{array}$ \\
\hline $\begin{array}{l}\text { Michel J. } \\
\text { Grothe, } \\
\text { PhD }\end{array}$ & $\begin{array}{l}\text { University of } \\
\text { Rostock }\end{array}$ & Author & $\begin{array}{l}\text { Interpreted the data, } \\
\text { revised the manuscript for } \\
\text { intellectual content }\end{array}$ \\
\hline $\begin{array}{l}\text { Stefan } \\
\text { Teipel, MD }\end{array}$ & $\begin{array}{l}\text { University of } \\
\text { Rostock }\end{array}$ & Author & $\begin{array}{l}\text { Interpreted the data, } \\
\text { revised the manuscript for } \\
\text { intellectual content }\end{array}$ \\
\hline $\begin{array}{l}\text { Henrik } \\
\text { Zetterberg, } \\
\text { MD, PhD }\end{array}$ & $\begin{array}{l}\text { University of } \\
\text { Gothenburg, } \\
\text { Mölndal, } \\
\text { Sweden }\end{array}$ & Author & $\begin{array}{l}\text { analyzed the data, revised } \\
\text { the manuscript for } \\
\text { intellectual content }\end{array}$ \\
\hline $\begin{array}{l}\text { Kaj } \\
\text { Blennow, } \\
\text { MD }\end{array}$ & $\begin{array}{l}\text { University of } \\
\text { Gothenburg, } \\
\text { Mölndal, } \\
\text { Sweden }\end{array}$ & Author & $\begin{array}{l}\text { analyzed the data, revised } \\
\text { the manuscript for } \\
\text { intellectual content }\end{array}$ \\
\hline $\begin{array}{l}\text { Marie-Odile } \\
\text { Habert, MD }\end{array}$ & $\begin{array}{l}\text { Sorbonne } \\
\text { University, Paris }\end{array}$ & Author & $\begin{array}{l}\text { Major role in the acquisition } \\
\text { of data, revised the } \\
\text { manuscript for intellectual } \\
\text { content }\end{array}$ \\
\hline $\begin{array}{l}\text { Marie C. } \\
\text { Potier, PhD }\end{array}$ & ICM, Paris & Author & $\begin{array}{l}\text { Analyzed the data, revised } \\
\text { the manuscript for } \\
\text { intellectual content }\end{array}$ \\
\hline $\begin{array}{l}\text { Bruno } \\
\text { Dubois, MD }\end{array}$ & $\begin{array}{l}\text { Sorbonne } \\
\text { University, Paris }\end{array}$ & Author & $\begin{array}{l}\text { Designed and } \\
\text { conceptualized study, } \\
\text { revised the manuscript for } \\
\text { intellectual content }\end{array}$ \\
\hline $\begin{array}{l}\text { Harald } \\
\text { Hampel, } \\
\text { MD, PhD }\end{array}$ & $\begin{array}{l}\text { Sorbonne } \\
\text { University, Paris }\end{array}$ & Author & $\begin{array}{l}\text { Designed and } \\
\text { conceptualized study, } \\
\text { interpreted the data, } \\
\text { revised the manuscript for } \\
\text { intellectual content }\end{array}$ \\
\hline
\end{tabular}

\section{References}

1. Sassin I, Schultz C, Thal DR, et al. Evolution of Alzheimer's disease-related cytoskeletal changes in the basal nucleus of Meynert. Acta Neuropathol 2000;100: 259-269.

2. Wu CK, Thal L, Pizzo D, Hansen L, Masliah E, Geula C. Apoptotic signals within the basal forebrain cholinergic neurons in Alzheimer's disease. Exp Neurol 2005;195: 484-496.

3. Mesulam M, Shaw P, Mash D, Weintraub S. Cholinergic nucleus basalis tauopathy emerges early in the aging-MCI-AD continuum. Ann Neurol 2004;55:815-828.

4. Geula C, Mesulam M. Special properties of cholinesterases in the cerebral cortex of Alzheimer's disease. Brain Res 1989;498:185-189.

5. Mesulam MM. Cholinergic circuitry of the human nucleus basalis and its fate in Alzheimer's disease. J Comp Neurol 2013;521:4124-4144.

6. Braak H, Zetterberg H, Del Tredici K, Blennow K. Intraneuronal tau aggregation 
precedes diffuse plaque deposition, but amyloid- $\beta$ changes occur before increases of tau in cerebrospinal fluid. Acta Neuropathol 2013;126:631-641.

7. Morris GP, Clark IA, Vissel B. Questions concerning the role of amyloid- $\beta$ in the definition, aetiology and diagnosis of Alzheimer's disease. Acta Neuropathol 2018; 136:663-689.

8. Vana L, Kanaan NM, Ugwu IC, Wuu J, Mufson EJ, Binder LI. Progression of tau pathology in cholinergic basal forebrain neurons in mild cognitive impairment and Alzheimer's disease. Am J Pathol 2011;179:2533-2550.

9. Grothe MJ, Ewers M, Krause B, Heinsen H, Teipel SJ, Initiative ADN. Basal forebrain atrophy and cortical amyloid deposition in nondemented elderly subjects. Alzheimers Dement 2014;10(5 suppl):S344-S353.

10. Teipel SJ, Meindl T, Grinberg L, et al. The cholinergic system in mild cognitive impairment and Alzheimer's disease: an in vivo MRI and DTI study. Hum Brain Mapp 2011;32:1349-1362.

11. Kilimann I, Grothe M, Heinsen H, et al. Subregional basal forebrain atrophy in Alzheimer's disease: a multicenter study. J Alzheimers Dis 2014;40:687-700.

12. Hampel H, O’Bryant SE, Molinuevo JL, et al. Blood-based biomarkers for Alzheimer disease: mapping the road to the clinic. Nat Rev Neurol 2018;14:639-652.

13. Mielke MM, Hagen CE, Wennberg AMV, et al. Association of plasma total tau level with cognitive decline and risk of mild cognitive impairment or dementia in the mayo clinic study on aging. JAMA Neurol 2017;74:1073-1080.

14. Mattsson N, Zetterberg H, Janelidze S, et al. Plasma tau in Alzheimer disease. Neurology 2016;87:1827-1835.

15. Mattsson N, Andreasson U, Zetterberg H, et al. Association of plasma neurofilament light with neurodegeneration in patients with Alzheimer disease. JAMA Neurol 2017; 74:557-566.

16. Liu AKL, Chang RCC, Pearce RKB, Gentleman SM. Nucleus basalis of Meynert revisited: anatomy, history and differential involvement in Alzheimer's and Parkinson's disease. Acta Neuropathol 2015;129:527-540.

17. Hampel H, O’Bryant SE, Durrleman S, et al. A precision medicine initiative for Alzheimer's disease: the road ahead to biomarker-guided integrative disease modeling. Climacteric 2017;20:107-118.

18. Hampel H, O’Bryant SE, Castrillo JI, et al. Precision medicine: the golden gate for detection, treatment and prevention of Alzheimer's disease. J Prev Alzheimers Dis 2016;3:243-259.

19. Dubois B, Epelbaum S, Nyasse F, et al. Cognitive and neuroimaging features and brain $\beta$-amyloidosis in individuals at risk of Alzheimer's disease (INSIGHT-preAD): a longitudinal observational study. Lancet Neurol 2018;17:335-346.

20. Cavedo E, Chiesa PA, Houot M, et al. Sex differences in functional and molecular neuroimaging biomarkers of Alzheimer's disease in cognitively normal older adults with subjective memory complaints. Alzheimers Dement 2018;14:1204-1215.

21. Olsson B, Lautner R, Andreasson U, et al. CSF and blood biomarkers for the diagnosis of Alzheimer's disease: a systematic review and meta-analysis. Lancet Neurol Engl 2016;15:673-684.

22. Gisslén M, Price RW, Andreasson U, et al. Plasma concentration of the neurofilament light protein (NfL) is a biomarker of CNS injury in HIV infection: a cross-sectional study. Ebiomedicine 2016;3:135-140.

23. Grothe M, Heinsen H, Teipel S. Longitudinal measures of cholinergic forebrain atrophy in the transition from healthy aging to Alzheimer's disease. Neurobiol Aging 2013;34:1210-1220.

24. Cavedo E, Grothe MJ, Colliot O, et al. Reduced basal forebrain atrophy progression in a randomized donepezil trial in prodromal Alzheimer's disease. Sci Rep 2017;7:1-10.

25. Mesulam MM, Mufson EJ, Levey AI, Wainer BH. Cholinergic innervation of cortex by the basal forebrain: cytochemistry and cortical connections of the septal area, diagonal band nuclei, nucleus basalis (substantia innominata), and hypothalamus in the rhesus monkey. J Comp Neurol 1983;214:170-197.
26. Mesulam MM, Geula C. Nucleus basalis (Ch4) and cortical cholinergic innervation in the human brain: observations based on the distribution of acetylcholinesterase and choline acetyltransferase. J Comp Neurol 1988;275:216-240.

27. Mathalon DH, Sullivan EV, Rawles JM, Pfefferbaum A. Correction for head size in brain-imaging measurements. Psychiatry Res Neuroimaging 1993;50:121-139.

28. Habert MO, Bertin H, Labit M, et al. Evaluation of amyloid status in a cohort of elderly individuals with memory complaints: validation of the method of quantification and determination of positivity thresholds. Ann Nucl Med 2018;32:75-86.

29. Van Belle G, Fisher LD, Heagerty PJ, Lumley T. Biostatistics: A Methodology for the Health Sciences, 2nd ed. Hoboken: Wiley; 2004.

30. Bollen KA, Jackman RW. Regression diagnostics: an expository treatment of outliers and influential cases. Sociol Methods Res 1985.

31. Shahim P, Tegner Y, Marklund N, Blennow K, Zetterberg H. Neurofilament light and tau as blood biomarkers for sports-related concussion. Neurology 2018;90:e1780-e1788.

32. Lewczuk P, Beck G, Ganslandt O, et al. International quality control survey of neurochemical dementia diagnostics. Neurosci Lett 2006;409:1-4.

33. Donker Kaat L, Meeter LH, Chiu WZ, et al. Serum neurofilament light chain in progressive supranuclear palsy. Park Relat Disord 2018;56:98-101.

34. Sandelius $\AA$, Zetterberg H, Blennow K, et al. Plasma neurofilament light chain concentration in the inherited peripheral neuropathies. Neurol Epub 2018;90:e518-e524.

35. Braak H, Thal DR, Ghebremedhin E, Del Tredici K. Stages of the pathologic process in Alzheimer disease: age categories from 1 to 100 years. J Neuropathol Exp Neurol 2011;70:960-969.

36. Shahim P, Tegner Y, Gustafsson B, et al. Neurochemical aftermath of repetitive mild traumatic brain injury. JAMA Neurol 2016;73:1308-1315.

37. Kubo A, Misonou H, Matsuyama M, et al. Distribution of endogenous normal tau in the mouse brain. J Comp Neurol 2019;527:985-998.

38. Ashton NJ, Leuzy A, Lim YM, et al. Increased plasma neurofilament light chain concentration correlates with severity of post-mortem neurofibrillary tangle pathology and neurodegeneration. Acta Neuropathol Commun 2019;7:5.

39. Tzen KY, Yang SY, Chen TF, et al. Plasma A $\beta$ but not tau is related to brain PiB retention in early Alzheimer's disease. ACS Chem Neurosci 2014;5:830-836.

40. Zetterberg H, Wilson D, Andreasson U, et al. Plasma tau levels in Alzheimer's disease. Alzheimers Res Ther 2013;5:9.

41. Chiu MJ, Chen YF, Chen TF, et al. Plasma tau as a window to the brain-negative associations with brain volume and memory function in mild cognitive impairment and early Alzheimer's disease. Hum Brain Mapp 2014;35:3132-3142.

42. Dage JL, Wennberg AMV, Airey DC, et al. Levels of tau protein in plasma are associated with neurodegeneration and cognitive function in a population-based elderly cohort. Alzheimers Dement 2016;12:1226-1234.

43. Deters KD, Risacher SL, Kim S, et al. Plasma tau association with brain atrophy in mild cognitive impairment and Alzheimer's disease. J Alzheimers Dis 2017;58:1245-1254.

44. Mesulam M. The cholinergic lesion of Alzheimer's disease: pivotal factor or side show? Learn Mem 2004;11:43-49.

45. Skillbäck T, Farahmand B, Bartlett JW, et al. CSF neurofilament light differs in neurodegenerative diseases and predicts severity and survival. Neurology 2014;83 $1945-1953$.

46. Preische O, Schultz SA, Apel A, et al. Serum neurofilament dynamics predicts neurodegeneration and clinical progression in presymptomatic Alzheimer's disease. Nat Med 2019;25:277-283.

47. Pereira JB, Westman E, Hansson O. Association between cerebrospinal fluid and plasma neurodegeneration biomarkers with brain atrophy in Alzheimer's disease. Neurobiol Aging 2017;58:14-29.

48. Petzold A, Tisdall MM, Girbes AR, et al. In vivo monitoring of neuronal loss in traumatic brain injury: a microdialysis study. Brain 2011;134:464-483.

49. Kinnunen KM, Greenwood R, Powell JH, et al. White matter damage and cognitive impairment after traumatic brain injury. Brain 2011;134:449-463. 


\section{Neurology}

\section{Plasma tau correlates with basal forebrain atrophy rates in people at risk for Alzheimer disease \\ Enrica Cavedo, Simone Lista, Marion Houot, et al. \\ Neurology published online December 4, 2019 \\ DOI 10.1212/WNL.0000000000008696}

This information is current as of December 4, 2019

\section{Updated Information \&} Services

Subspecialty Collections

Permissions \& Licensing

Reprints including high resolution figures, can be found at: http://n.neurology.org/content/early/2019/12/04/WNL.0000000000008 696.full

This article, along with others on similar topics, appears in the following collection(s):

Alzheimer's disease

http://n.neurology.org/cgi/collection/alzheimers_disease Volumetric MRI

http://n.neurology.org/cgi/collection/volumetric_mri

Information about reproducing this article in parts (figures,tables) or in its entirety can be found online at:

http://www.neurology.org/about/about_the_journal\#permissions

Information about ordering reprints can be found online:

http://n.neurology.org/subscribers/advertise

Neurology ${ }^{\circledR}$ is the official journal of the American Academy of Neurology. Published continuously since 1951, it is now a weekly with 48 issues per year. Copyright (O 2019 American Academy of Neurology. All rights reserved. Print ISSN: 0028-3878. Online ISSN: 1526-632X.

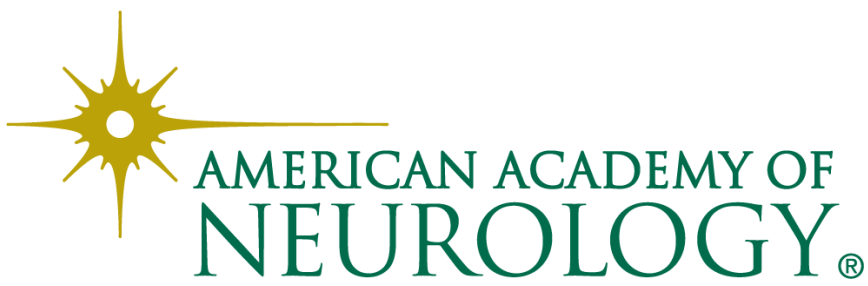

